\title{
P02-145
}

\section{ABDUCTION OF CHILDREN BY THEIR PARENTS: THE PSYCHOPATHOLOGICAL APPROACH OF THE PROBLEM IN MIXED-ETHNICITY MARRIAGES}

K. Kontoangelos ${ }^{1}$, A. Douzenis ${ }^{2}$, L. Lykouras ${ }^{2}$, G. Papadimitriou ${ }^{1}$

${ }^{1} 1$ st Department of Psychiatry, Eginitio Hospital, ${ }^{2}$ 2nd Department of Psychiatry, Attiko Hospital, University of Athens, Medical School, Athens, Greece

Introduction: Children abduction by one parent and their transport refers to a foreign country is a gradually increasing phenomenon worldwide as well as Greece. Data from the Greek Ministry of Justice show that the frequency of such incidences is up to one a day (360/year). Some but not all of these cases come to the attention of the International Social Services (Division of Greece).

Method: Records of fifty (50) cases of inter family abduction were obtained. These were cases that took place during the year 2003. These records were studied and analysed. The majority of cases concerned abductions within the European Union. Permission from the Personal Data Protection service was obtained before the research.

Results: It was found that fathers were predominantly the abductors $(60 \%)$. Based on the medical records of the parents, the abductor had established psychopathology (fathers $51,1 \%$; mothers $48,5 \%$ ). The abducting fathers made significant use of violence $(50 \%)$ compared to the mother abductors $(20 \%)$. The legal procedures that ensued the abductions were particularly prolonged: The trial period until the reach of a verdict took an average of 3 years.

Conclusions: In the cases of children abduction by a parent, there is high correlation between the action and the psychopathology of the abductor. The need for establishment of services appropriate to face this multidisciplinary problem is imminent. The long time each case takes to be resolved has obvious implications for the mental health of the children and the parents involved. 